\title{
Atmospheric dust-induced calcification of lungs
}

\author{
M. JABŁOŃSKA ${ }^{1}$, J. JANECZEK ${ }^{1 *}$
}

${ }^{1}$ Institute of Earth Sciences, University of Silesia, Będzińska 60, 41-200 Sosnowiec, Poland

(mariola.jablonska@us.edu.pl)

${ }^{1}$ (*correspondence: janusz.janeczek@us.edu.pl)

For the first time the lung calcification is related to ambient atmospheric dust particles inhaled by inhabitants of urban areas not occupationally exposed to mineral dust. Biogenic calcite and Mg-calcite (29 to $53 \mathrm{~mol} \% \mathrm{MgCO}_{3}$ ) constitute a majority of mineral particles observed by SEM/TEM in the autopsy samples of tissues from right lower lobe (RLL) of 12 residents (4 females and 8 males, aged 18 to 89 at time of death not caused by lung diseases) of the highly urbanized and industrialized region of the Upper Silesian Conurbation, Poland. Carbonates occur either as single grains or aggregates of grains in the $0.2-7 \mu \mathrm{m}$ size range. Mg-calcite amounts to about $80 \%$ of submicron-size carbonate particles and is absent in particles larger than $1 \mu \mathrm{m}$. The amount of carbonates in RLL is age-dependent ranging from $5.48 \mathrm{vol} \%$ in tissues of 18 year old female smoker to $64.62 \mathrm{vol} \%$ in tissues of 82 year old female non-smoker.

Precipitation of calcium carbonates was induced by inhaled exogeneous particles settled in RLL as suggested by observations of uraninite and $\mathrm{Fe}-, \mathrm{Zn}-$, and $\mathrm{Pb}$-sulfides particles partially or entirely engulfed by either amorphous calcium carbonate (ACC) or calcite. The following sequence of mineral dust-induced calcification is inferred from these observations: a) inhaled dust particles trigger the phagocytosis; b) the insoluble dust particles are coated by ACC; c) the ACC transforms into calcite or Mg-calcite.

The actual number of dust particles settled in RLL may be significantly higher than observed, due to the masking effect of calcite and Mg-calcite.

Negligible number of calcium phosphate (bioapatite) particles observed in this study is in stark contrast with literature data that report hydrooxyapatite as a predominant product of dystrophic calcification [1]. The specific environment of lungs lower lobe, namely relatively low ventilation to perfusion ratio and $\mathrm{pH} 7.39$ [1], favors precipitation of carbonates rather than phosphates.

[1] Chan et al. (2002) Am. J. Respir Crit Care Med 165, 1654-1669. 